\title{
Metagenomic profiling of gut microbiota in urban and rural rats: A comparative study
}

Rafig GURBANOV ( $\nabla$ rafig.gurbanov@bilecik.edu.tr)

Bilecik Şeyh Edebali Üniversitesi: Bilecik Seyh Edebali Universitesi https://orcid.org/0000-0002-52936447

\section{Uygar KABAOĞLU}

Bilecik Şeyh Edebali Üniversitesi: Bilecik Seyh Edebali Universitesi

\section{Tuba YAĞCI}

Bilecik Şeyh Edebali Üniversitesi: Bilecik Seyh Edebali Universitesi

Keywords:

Posted Date: February 12th, 2021

DOI: https://doi.org/10.21203/rs.3.rs-211015/v1

License: (c) (1) This work is licensed under a Creative Commons Attribution 4.0 International License. Read Full License 


\section{Abstract}

The authors have requested that this preprint be removed from Research Square. 